AperTO - Archivio Istituzionale Open Access dell'Università di Torino

Do tourists experience boredom in mountain destinations?

This is a pre print version of the following article:

Original Citation:

Availability:

This version is available http://hdl.handle.net/2318/1805276

since 2021-09-26T07:28:58Z

Published version:

DOI:10.1016/j.annals.2021.103213

Terms of use:

Open Access

Anyone can freely access the full text of works made available as "Open Access". Works made available under a Creative Commons license can be used according to the terms and conditions of said license. Use of all other works requires consent of the right holder (author or publisher) if not exempted from copyright protection by the applicable law. 


\title{
Do tourists experience boredom in mountain destinations?
}

\author{
Chiara Mauri $^{\mathrm{a}, *}$, Consuelo R. Nava ${ }^{\mathrm{b}}$ \\ ${ }^{a}$ Università di Castellanza LIUC, Piazza Soldini, 5 - Castellanza, 21053, Italy \\ ${ }^{\mathrm{b}}$ Università degli Studi di Torino, Italy
}

\section{A R T I C L E I N F O}

\section{Article history:}

Received 27 August 2020

Received in revised form 8 April 2021

Accepted 12 April 2021

Available online $\mathrm{xxxx}$

Associate editor: Rossello Jaume

\section{Keywords:}

Boredom

Leisure-Boredom Scale

Winter mountain tourism

Tourism motivation

Tourist activities

Tourism expenses

\begin{abstract}
A B S T R A C T
The paper investigates the extent to which tourists perceive boredom during their winter mountain holiday. The Leisure Boredom Scale (S.E. Iso-Ahola \& Weissinger, 1990) was applied to segment tourists on the base of their perceived boredom. An empirical research operated in an Alpine region revealed the existence of two segments who experience boredom: Bored tourists and Excited-Bored tourists (21\% of the tourists). This evidence contradicts results found in previous literature that boredom is associated to passive behaviour, and shows that boredom co-exists with excitement. The majority of these tourists are mothers accompanying their relatives, stay in hotels, and choose either the chief town Aosta or minor locations. Bored tourists are involved in many activities, and spend even more than other tourists.
\end{abstract}

(c) 2021 Elsevier Ltd. All rights reserved.

\section{Introduction}

A recent empirical study performed in three mountain destinations with the objective of understanding tourist preferences for different holiday packages, unexpectedly revealed that a significant portion of winter mountain tourists perceived their holidays as monotonous. Despite describing their vacation as monotonous, the days of these tourists appeared full of many different activities, none of which seemed to dominate. This group represented $10 \%$ to $23 \%$ of the tourists depending on the destination, and included many women accompanying their relatives and friends (Mauri \& Turci, 2018; Mauri, 2019) .

To the best of our knowledge, no studies have been conducted to investigate the boredom experience in tourism. Thus, the goals of our research are to measure the existence of boredom during winter mountain holiday and to investigate its intensity and the extent to which boredom translates into passive behaviour.

On the one side, tourism per se is almost always interpreted as a positive and exciting leisure experience (Morgan et al., 2010; Smith \& Godbey, 1991) to be lived, remembered and recounted (Kim et al., 2012); on the other side, boredom has often been analysed more as a feeling that stimulates tourism rather than a feeling perceived while practicing it (Iso-Ahola \& Weissinger, 1990; Lee \& Crompton, 1992; Ryan \& Glendon, 1998).

However, leisure is not always a satisfactory freedom and may carry the risk of boredom (Iso-Ahola and Weissinger, 1990). Tourism, as well as leisure, can be considered an unstructured time, or at least a time much less busy than daily routine; hence, tourists may perceive that they have too much time on their hands with too little to do to fill that time (Iso-Ahola \& Weissinger, 1987; Shaw, Kleiber, \& Caldwell, 1995). This sensation may be further enhanced in all the situations in which tourists feel compelled to participate in outer-directed activities, or in activities that they consider frustrating and/or monotonous (Hill \& Perkins, 1985).

\footnotetext{
* Corresponding author.

E-mail addresses: cmauri@liuc.it, (C. Mauri), consuelorubina.nava@unito.it. (C.R. Nava).
} 
Winter mountain destinations may represent an ideal context to study if, and how much, tourists experience boredom during their holiday. The predominance of outdoor recreation and snow sports, paired with shorter daylight hours and more severe weather conditions, may significantly limit tourist activities. Moreover, winter mountain destinations are relatively calmer and quieter environments compared to other holiday destinations (Silva et al., 2013); spaces are more constrained and often almost all the attractions are within arm's reach. These characteristics leave more free time to fill, and potentially "too much time available and too little to do" (Iso-Ahola and Weissinger, 1990). Eventually, the only empirical evidence which suggests the potential existence of a boredom perception during holidays emerged right in winter mountain destinations (Mauri, 2019).

Given these considerations, the goal of this paper is to shed some light on boredom as the neglected side of the tourism experience: do tourists experience boredom during their winter mountain holidays? Are bored tourists passive tourists (Derek et al., 2019) or unimaginative relaxers (Ryan \& Glendon, 1998)? Or, on the contrary, do they engage in the same or even more varied activities than non-bored tourists? How much are they satisfied with their holiday? Do they spend more or less money than nonbored tourists? An empirical research made on a sample of tourists during their winter mountain holiday tries to address these questions.

\section{Theoretical background}

Since the goal of this research is to investigate the extent to which tourists experience boredom during their winter mountain holidays, we are interested in a) segmenting them on the base of their perception of boredom, b) describing their profile also on the base of their values and motivations, c) analysing how they distribute their time between different activities, and d) measuring the expenses related to these activities.

Given that boredom perception is influenced by both personal and situational characteristics (Iso-Ahola and Weissinger, 1990), to further profile segments we need to investigate on the one side personal values and tourism motivations, and on the other side the activities that can be undertaken in a specific winter mountain destination. Activities are, in fact, key components of the situational characteristics, because winter and mountain put significant constraints on the schedule of the tourist's day.

In this perspective, the theoretical background of this paper is grounded on four main streams of literature: perception of boredom in leisure, tourists' values and motivations, tourism activities, and tourism expenditures.

\section{Tourism, leisure, and boredom in leisure}

The first stream of literature is related to tourists' perception of boredom in leisure and to its measurement (Iso-Ahola and Weissinger, 1990).

Research has frequently associated tourism with leisure, interpreting the tourism experience as a leisure experience, that is, an experience lived in leisure time (Morgan et al., 2010; Carr, 2002; Mannell \& Iso-Ahola, 1987; Pechlaner \& Smeral, 2014). Both tourism and leisure are unstructured time, and require that individuals think, plan and organize the time that they have at their disposal. When they are not able to use and organize this free time, they may feel like they are in a state of low arousal and perceive a sense of monotony and boredom (Haller, Hadler, \& Kaup, 2013; Iso-Ahola \& Weissinger, 1990; Wang, Wu, Wu, \& Huan, 2012). Since this situation can create stress, holiday-takers may look for additional or alternative stimulation to reach a higher level of satisfaction and arousal (Fiske \& Maddi, 2012). While research has shown that people may feel bored in leisure time, to the best of our knowledge no studies have been conducted to directly investigate the boredom experience in holiday time; holidays are thought of as an escape from everyday life, and seen as a break from daily stress and routine (Lee \& Crompton, 1992).

Vodanovich (2003) observes that there is not a universally accepted definition of boredom, and this has resulted in diverse approaches to assessing various subsets of boredom. Phillips (1993) had already noticed that there is not one single type of boredom; rather, there are "boredoms", each with its own specific moods and feelings, one of which being leisure or free-time boredom. Even if it may be surprising to discover that people may feel bored in leisure time, Iso-Ahola and Weissinger (1987) supposed that boredom could simultaneously coexist with leisure, a relationship that has also been confirmed in more recent research (Barnett, 2005; Barnett \& Klitzing, 2016; Miller et al., 2014). The key point emerging from these studies is that the abundance of unstructured time is a factor of boredom.

Boredom is a psychophysiological state of low arousal that is attributed to an inadequately stimulating environment (Mikulas \& Vodanovich, 1993; O'hanlon, 1981), but most studies agree that what matters is not the objective monotony of the situation, but rather its subjective perception. Hence, the same situation may appear boring to some individuals and non-boring to others.

Boredom is inversely related to the level of satisfaction people derive from their leisure time and from their willingness to engage in personally satisfying leisure experiences (Barnett, 2005). In this perspective, people used to having a structured everyday life may fear boredom even before perceiving it, and, hence, book their leisure time so as to engage in many activities. If this hypothesis were true, individuals who fear boredom during their holiday would find themselves in a seeking state that prompts them to explore many alternative experiences (Bench \& Lench, 2019).

The most widely used scale to measure boredom is the Boredom Proneness Scale (BPS) developed by Farmer and Sundberg (1986). Factor analytic studies of the BPS scale have indicated the existence of two to five factors, but the large agreement is on two: the perception of low environmental stimulation and the ability of individuals to engage in exciting activities for themselves. BPS scores have been found to be positively related with measures of negative attitudes, intellectual and physical inactivity and poor attentional control (Vodanovich, 2003). 
Since the BPS scale is a general measure of boredom and given the existence of different types of boredom, the BPS scale may not be the ideal instrument to investigate specific types of boredom, such as boredom in leisure time. Iso-Ahola and Weissinger (1987) developed the Leisure-Boredom Scale (LBS), and on the same wavelength Ragheb and Merydith (2001) proposed the Free Time Boredom Scale (FTB), both scales measuring an important aspect of boredom: how people perceive and use their unstructured time. The LBS scale consists of 16 items that ask people how they feel about their leisure time, while the FTB scale is composed of 33 items. Since Ragheb and Merydith (2001) found that the FTB total score is correlated with the BPS score, we choose the more parsimonious BPS scale.

Tourists' value system and tourism motivations

The second stream of literature rests on tourists' value system and motivations.

Personal values lie behind tourism motivations when choosing a particular place as a holiday destination, and tourism literature has justified value surveys as a preliminary step to investigate motivations (Baloglu \& Uysal, 1996; Madrigal \& Kahle, 1994). The complex interplay between values (Madrigal \& Kahle, 1994; Li \& Cai, 2012), internal/push and external/pull factors (Baloglu \& Uysal, 1996; Dann, 1977, 1981), motives and motivations (Gnoth, 1997), functional themes (Fodness, 1994), suggests applying more than one measurement tool to have a deeper understanding of tourism behaviour in a particular context.

One of the most commonly used instruments to measure personal values has been the Rokeach's Value Survey (RVS, Rokeach, 1973), consisting of 18 instrumental values and 18 terminal values. In 1983, Kahle introduced the more parsimonious List Of Values (LOV), consisting of only 9 items derived from the list of terminal values of the RSV: sense of belonging, excitement, fun and enjoyment in life, self-fulfilment, being well respected, warm relationships with others, security, accomplishment, and self-respect. These nine values were considered to relate more closely to the values of life's major roles compared to the values of the RVS scale (Kahle et al., 1986).

Holidays and tourism have been evolving in parallel with cultural developments, because vacation is intimately connected to the concepts of individual self-expression and self-actualization (Gnoth, 1997). When applied for the purpose of analysing crosscultural differences, the results of the LOV scale have, however, been surprising and not in line with the literature on the local culture (Watkins \& Gnoth, 2005). This evidence implies that when the tourists under study come from different countries, caution must be used when interpreting the results emerging from the application of the LOV scale.

Personal values interplay with motives, motivations, and with the objective situation in the process of attitude formation (Gnoth, 1997). The LOV scale can, therefore, be complemented by another measurement tool to have a more complete overview of the tourism motivations and, given the purpose of this research, of the possible reasons behind boredom. Tourists' motivations can be investigated according to different perspectives depending on the specific interpretation of motivations, on their types, on their components, and on the objectives of the research (for a conceptual, methodological, and empirical treatment of the concept of tourist motivation, widely cited papers are Crompton (1979), Dann (1977, 1981), Pearce \& Caltabiano (1983), Gnoth (1997)). Besides, given that the choice of a specific holiday is very often a family decision (Thornton et al., 1997; Lehto et al., 2009; Decrop \& Snelders, 2004) and/or a decision delegated to social surrogates (Stone, 2016), different motivations of the family members may generate a conflict, whose end result is a compromise between pleasure and duty.

For our purposes, a useful tool to measure motivations is the scale developed by Fodness (1994), which is intended to measure the psychological functions the vacation serves for individuals. The scale consists of 20 items representing three macro-functions: knowledge, utilitarian, and value expressive. The knowledge function is related to the escape from everyday life to see new places and to discover new cultures, while the utilitarian function is connected not so much with the discovery but rather with the escape from the pression and stress of everyday life. Finally, the value expressive function is more related to the match between the type of person and the type of destination.

\section{Tourist activities in winter mountain destinations}

The third stream of literature is related to the activities practiced by tourists. The characteristics of mountain areas influence the practice of touristic activities (Nepal \& Chipeniuk, 2005). The mountain activities that can be practiced in wintertime are different from those that can be practiced during summer, and shorter daylight and severe weather conditions are a further burden that constrains the activities that can be made. If on the one side winter mountain holidays are almost by default associated with skiing (Frochot et al., 2017; Heberlein et al., 2002), on the other side the research done by Mauri and Turci (2018) has identified sixteen activities that drive the segmentation of winter mountain tourists. These activities could be read as the link between travel motivations and destination choice (Moscardo et al., 1996; Derek et al., 2019), and, as such, they can be interpreted as both a synthesis and a realization of travel motivations.

Activities can be studied in terms of the packages chosen by different tourist segments, such as in Mauri and Turci (2018), in terms of their perceived importance, such as in Madrigal and Kahle (1994), and also in terms of time spent (Pearce, 1988).

The list of activities practiced by tourists can be complemented by their related expenditures (Kozak et al., 2008; Fredman, 2008; Sainaghi, 2012), which give a full understanding of the total economic value associated to mountain tourism.

\section{Tourist expenses}

The last stream of literature are the tourists' expenses, a topic widely studied from different perspectives, both at the aggregate and at the disaggregate level (Dolnicar et al., 2008): at geographic, industry segment and type of destinations level for the first; at 
the level of tourists' segments, households and individual tourists for the second (for a review, see for instance Sainaghi, 2012). Moreover, expenses can be studied from the perspective of their determinants or of their allocations between different activities (Choong-Ki et al., 1996; Aguiló et al., 2017, Kozak et al., 2008; Rosselló-Nadal \& He, 2020).

Given the purpose of our research, we are interested in studying the allocation of tourist expenses for different activities at a disaggregate level, to understand how they might differ between the segments identified in terms of boredom perception. Apart from the destination choice, tourists are required to make a lot of decisions during their winter mountain holiday, involving aspects such as accommodation, sport practice, restaurants, cultural attractions, etc. (Park et al., 2020).

For example, the study done by Derek et al. (2019) reveals that passive tourists are the least active segment, and also the ones with the second lowest total expenditures, because they do not participate in activities that require significant amounts of money for equipment. While their journey and accommodation costs are similar to those of the other segments, their use cost is almost zero. Passivity in that study is interpreted as a state of low involvement in those activities that require both technical equipment and skills, in the sense that passive tourists practice activities that can be done almost anywhere. Boredom, instead, is not necessarily associated with inactivity. As we mentioned in the introduction, there is evidence that tourists who perceived their holidays as monotonous were spending their days in many activities, none of which was dominant (Mauri, 2019) and their expenses did not appear lower compare to other segments.

\section{Methodology}

The framework of our research is organized in the following four steps (Fig. 1):

1. segmentation of winter mountain tourists on the basis of their perceived boredom;

2. analysis of the tourists' values and motivations in the identified segments;

3. analysis of the activities practiced by segments;

4. comparison of the expenses for each activity between segments.

Boredom is measured using the LBS scale, which consists of 16 items. In the present research only 14 of them were selected and were contextualized to the specific situation. Two items were deleted because they were not relevant in a holiday situation (e.g. "If I could retire now with a comfortable income, I would have plenty of exciting things to do for the rest of my life"); for contextualization, for instance the original item "For me, leisure time just drags on and on" has been rephrased as "For me, winter mountain holidays just drag on and on"; the original item "Leisure time is boring" has been rephrased as "Winter mountain holidays are boring". We also used two single-item indicators of boredom as control questions, as proposed in Iso-Ahola and Weissinger (1990).

The LOV scale (Madrigal \& Kahle, 1994) was used in order to investigate the most important values for people in their daily lives. The scale, originally made up of 9 points, was uniformed to a 7-points scale, as in Li and Cai (2012). Previous literature has alerted to the risk of end-piling in this kind of scale, where individuals tend to rate all the values high, and has suggested to overweight respondents' single most important value(s) (Madrigal \& Kahle, 1994). Given the very high average rates of all the items of the LOV scale (mean $=6.05$, median 6.22 ), the over-weight of the highest values did not add significant discrimination. Therefore, we binarized the ratings of the LOV scale assigning $7=1$ and all the other agreement levels equal to zero, as in Lengieza et al. (2019). The segments identified on the basis of the LBS scale have then been compared in terms of the distribution of both their values (LOV scale) and motivations (Fodness scale) (Fodness, 1994). The ratings of the Fodness scale have been binarized as has been done for the LBS scale, and the results have been used to compare the segments in terms of their motivations.

The activities practiced in winter mountain destinations have been identified crossing Mauri and Turci (2018), Moscardo, Morrison, Pearce, Lang, and O'Leary (1996), and Madrigal and Kahle (1994). The final list includes twelve activities: alpine and cross-country skiing, hiking in the snow (including with snowshoes), wellness and relaxation (including hot springs), restaurants and traditional food, visit monuments and museums, nightlife and casinos, reading books, accompanying husband/wife/children in their activities, sleeping (not at night-time), shopping, meeting friends (excluding restaurant), and participating in local events.

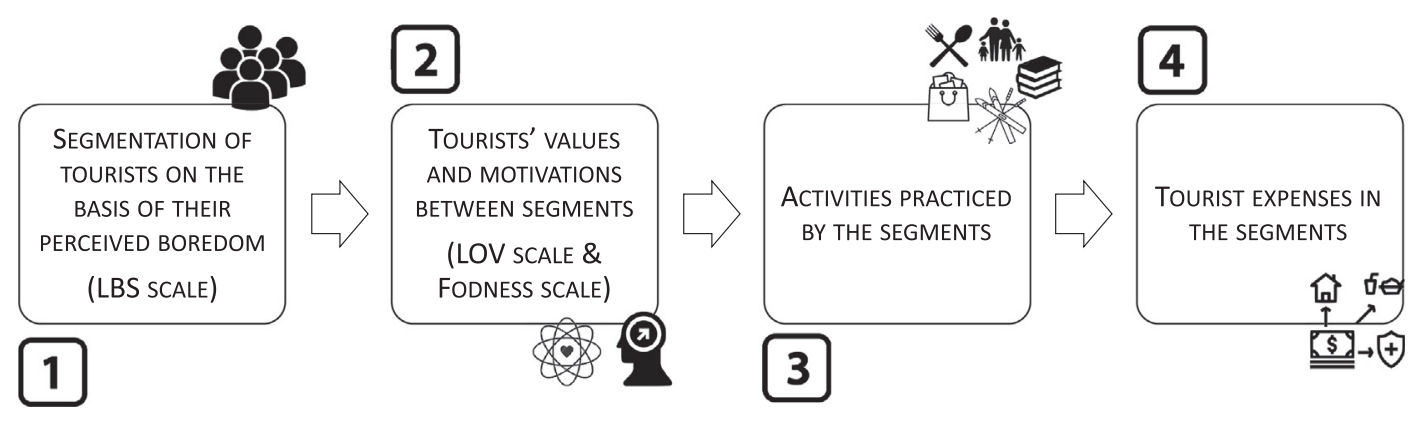

Fig. 1. Framework of the research. 
The activities were integrated with their related expenditures and were complemented by the accommodation expenditures to determine a grand total, as in Davies and Mangan (1992). Travel expenses were excluded. The specific question related to the expenditures was: "Think about your activities during this holiday (keeping in mind the days left until the end) and indicate how much you spend/think of spending for you and your family overall. Specify the amount in euros". The estimate of tourist spending applies the model of "total gross spending" (Kozak et al., 2008), inclusive of companions and vacation days. To facilitate respondents' answers, the question was phrased considering that some expenditures are a lump sum for the total length of the holiday and for the family/group as a whole, as is the case for the hotel. This grand total would have also allowed for applying a second model - "daily spending per person" - determined by dividing the grand total by both the length of stay and the number of people in the group.

A survey was administrated to a total sample of 388 tourists visiting Aosta Valley February to May 2018. Respondents were reached through a multi-channel distribution system: surveyors, QR code, mailing lists, social media, and links on tourist web pages. Respondents were also recruited in hotels, skiing schools, slopes, shops, and restaurants. Completion rate was $92 \%$, coherent with Liu and Wronski (2018), and the initial sample size was of 357 complete questionnaires.

The majority of the sample (77.6\%) is composed of Italian citizens, followed by French (6\%), Swiss (5\%), English (4\%) Austrian (2\%), and other nationalities (4.4\%). First, data were analysed for the total sample; then, a second analysis was performed focusing only on Italian tourists to observe if there were significant differences between tourists coming from different countries. Given the way the questionnaire was distributed, respondents were free to participate in the survey, which explains why respondents come from different countries. However, the Hofstede's model of culture, which was checked as a preliminary step, showed differences in all its six dimensions between Italy, France, Switzerland and the UK. This evidence, coupled with the significantly longer stay for foreign tourists compared to that of the Italian ones and with relatively small numbers of foreign respondents for each country, were the reasons that suggested taking a more prudent approach and to consequently focus the analysis on the macrosegment of Italian tourists. Therefore, we conducted our analysis on a sample of 277 Italian respondents.

The profile of the final sample is the following:

- mean age: 39 years;

- women: $57 \%$;

- employed: $32 \%$, followed by students (17\%) and independent professional workers (16\%);

- average length of stay: 4.4 days;

- chosen accommodation: 37\% hotel, 28\% vacation home, 17\% rented apartment (Airbnb platform), 9\% residence, 7\% B\&B.

Of the 277 respondents, $25 \%$ usually take winter mountain holidays, and $75 \%$ of them had already been in the Aosta Valley for their winter holidays. Thirty-four percent of respondents are mothers, $23 \%$ are sons/daughters, $18 \%$ are fathers, the other respondents are friends and other relatives. Forty-nine percent of the sampled tourists came on holiday with their family, $22 \%$ with their partner and $15 \%$ with their friends; the remaining were on holiday alone or with both family and friends.

\section{Analysis of results}

\section{Segmentation of tourists on the basis of their perceived boredom}

Tourists were segmented on the basis of their ratings on the LBS scale, framed as a 7-point agreement scale. The scale consists of 14 items (see Table 1), which respondents had to rate from 1 (strongly disagree) to 7 (strongly agree). The scale contains 6 items related to "excitement" and 8 items related to "boredom"; S.E. Iso-Ahola and Weissinger (1990) alert to reverse the coding of the excitement items to make them coherent with the boredom items to subsequently operate a factor analysis.

Iso-Ahola and Weissinger (1990) proved the reliability and validity of the LBS scale in three studies through factor analysis and correlation analysis, thus implicitly treating the LBS scale as an interval scale. However, agree-disagree scales are ordinal, and there are controversies on their use as interval scales in clusterisation (Dolnicar et al., 2018). These controversies can be handled by translating from the original numeric/labelled answer format to a binary answer format using some criteria to split the scale (Dolnicar and Grün, 2013). This transformation is fundamental to apply metrics, such as the Euclidean distance to perform a segmentation.

Thus, for the segmentation analysis, we first reversed the excitement items, and then we translated the scale from Likert-type to binary-type, grouping the three agreement levels as " 1 ", and the three disagreement levels and the middle point as "0" (Dolnicar and Grün, 2013). Such transformation would probably be conservative in relation to the agreement level, and hence perhaps lend to underestimating the real level of tourists' perceived boredom. ${ }^{1}$ Moreover, our choice to focus only on Italian tourists allows for controlling for cross-cultural responses styles (Dolnicar and Grün, 2007). As recommended by Dolnicar and Grün (2008), we will not apply the "factor cluster segmentation" used in previous similar studies, but we cluster the binary answers directly to segment tourists on the basis of their perceived boredom.

Table 1 shows the mean values of the LBS items given the original 7-point scale and the transformed binarized one, together with the corresponding values for the reversed excitement items. For example, the item "During my winter mountain holiday, I

\footnotetext{
1 This conclusion is taken from the results of Dolnicar and Grün (2013), which however concerned brand image measurement. The same authors advise that their conclusions cannot be generalized to other contexts, but they expect that replications would find the same base tendencies. Moreover, the proposed binarization is based on the desire to isolate agreement responses from all the other response options. A similar approach can also be found in Lengieza, Hunt, and Swim (2019).
} 
Table 1

Mean rates of the 14 items of the original (left) and binarized (right) LBS scale together with the recoded values of the excitement items denoted with *.

\begin{tabular}{|c|c|c|c|c|}
\hline $\begin{array}{l}\text { Mean value } \\
(1-7)\end{array}$ & $\begin{array}{l}\text { Reversed } \\
(1-7)\end{array}$ & LBS items & $\begin{array}{l}\text { Mean value } \\
(0-1)\end{array}$ & $\begin{array}{l}\text { Reversed } \\
(0-1)\end{array}$ \\
\hline 5.06 & 1.94 & "During my winter mountain holiday, I become highly involved in what I do" * & 0.67 & 0.33 \\
\hline 5.09 & 1.91 & "I am excited about winter mountain holiday time" * & 0.65 & 0.35 \\
\hline 2.83 & & "For me, winter holiday just drugs on and on" & 0.19 & \\
\hline 2.57 & & "During my winter mountain holiday, I feel like I am just spinning my wheels" & 0.19 & \\
\hline 2.68 & & "In my winter mountain holiday, I usually don't like what I'm doing, but I don't know what else to do" & 0.19 & \\
\hline 4.60 & 2.40 & "Winter mountain holidays experiences are an important part of my quality of life" * & 0.51 & 0.49 \\
\hline 2.57 & & "Winter mountain holidays are boring" & 0.18 & \\
\hline 4.28 & 2.72 & "In my winter mountain holidays, I like to try new activities that I have never tried before" * & 0.45 & 0.55 \\
\hline 3.03 & & "In my winter mountain holiday, I want to do something, but I don't know what I want to do" & 0.23 & \\
\hline 4.61 & 2.39 & "In my winter mountain holiday, I almost always have something to do" * & 0.52 & 0.48 \\
\hline 3.17 & & "I waste too much of my winter mountain holiday time sleeping" & 0.23 & \\
\hline 4.55 & 2.45 & "I am very active during my winter mountain holiday" * & 0.52 & 0.48 \\
\hline 3.00 & & "Winter mountain activities do not excite me" & 0.23 & \\
\hline 3.01 & & "I do not have many leisure skills" & 0.23 & \\
\hline
\end{tabular}

become highly involved in what I do" has an original mean value of 5.06 and a reversed one of 1.94 . Similarly, it has a binarized mean value of 0.67 and a reversed binarized mean value of 0.33 .

In order to segment respondents, a hierarchical cluster analysis, using the Ward's method and the Euclidean distance, was carried out considering the binarized items and the reversed codes of the excitement items. We extract five clusters, whose leisure-boredom profile is shown in Fig. 2. However, to ease the interpretation of the segment profiles, results in Figs. 2 and 3 and associated comments are presented in the original (non-reversed) binarized codes.

Segment 1 (labelled S1, 57 tourists, 21\% of the sample) includes the tourists who scored low on all LBS items, that is, they are not very involved, they are not excited, they do not try new activities. Yet, at the same time, they do not perceive they are wasting their time, and neither do they admit feeling bored. Thus, this segment can be labelled "Non-Involved tourists". Segment 2 is the largest (S2, 88 tourists, 32\% of the sample) and includes the real fans of winter mountain holidays, which they consider to be an important component of their quality of life. They are very active during their days and they have always something to do, so there is no room for boredom. Therefore, S2 is named "Winter Mountain Fans". Segment 3 (S3) is the smallest (9\%): in spite of being highly involved and active, they perceive a higher level of boredom compared to the first two segments. Their apparently contradictory situation shows that leisure does not exclude boredom, and also that involvement and enthusiasm can coexist with boredom. This coexistence suggests that S3 could be labelled "Excited-Bored tourists". Segment 4 (S4, 32 tourists, 12\%) includes the bored tourists, whose behaviour can be seen as the opposite of S2: they score high on all the items related to boredom and low on the items related to involvement and excitement; hence, they are named "Bored tourists". Finally, tourists of Segment 5 (S5, 75 tourists, 27\%) appear to be the closest to the average: they are not significantly higher on all the items related to involvement and excitement and are significantly lower in the perception of boredom. Thus, S5 is composed of "Neither Bored nor Excited tourists".

The 14 items of the LBS scale can be grouped into two categories: excitement ( 6 items) and boredom ( 8 items). Given the relative high consistency with which respondents have expressed their agreement on both the first and the second items (all high or all low), we can calculate the average for each category and build a bi-dimensional map of the five segments (Fig. 3 ). ${ }^{2}$

This figure reveals new insights on the "shape" of the five segments and on their internal configuration. Tourists of S2, the fans of winter mountain holidays, appear to be the most homogeneous in terms of their excitement/boredom feelings, while the tourists of all the other four segments are more dispersed. Excited-Bored tourists (S3) and Bored tourists (S4) show a relatively large internal dispersion, while the other segments show some more sub-grouping. The area of low boredom is much more densely populated, with tourists of S1, S2 and S5. Seen in this perspective, some segments overlap partially, with tourists of different segments located in very close positions. This is true particularly for the Fans and the Neither Bored nor Excited tourists.

To further refine the segmentation scheme, we added up the scale values of the 7-point LBS and then compared tourists in the fourth (highest values) and in the first (lowest values) quartiles. As can be seen in Table 2, most of the tourists in the top quartile are included in the Excited-Bored and in the Bored segments, but for different reasons: the first tourists rate high items related to both excitement and boredom, even if the latter to a lower extent, while Bored tourists rate significantly higher the items related to boredom and lower the ones related to excitement.

The remarkable differences between the five segments in terms of accommodation and chosen location can be summarized in the followings. Tourists who experience boredom in their holiday principally stay in hotels. The percentage of tourists of the two segments S3 and S4 who have chosen hotels is higher than the average, and significantly higher for S4. The same two segments show differences in their choice of the location: Bored tourists (S4) are more concentrated in Pila, while a higher percentage of S3 tourists chose the city of Aosta. Staying in the chief town Aosta does not limit access to ski domains: there is a cableway that in only 18 min carries skiers from the city centre to Pila, a well-known ski domain. The chief town Aosta is a very quiet city: it is

\footnotetext{
2 Only for graphical purposes, a small uniform perturbation is introduced between -0.03 and 0.03 .
} 


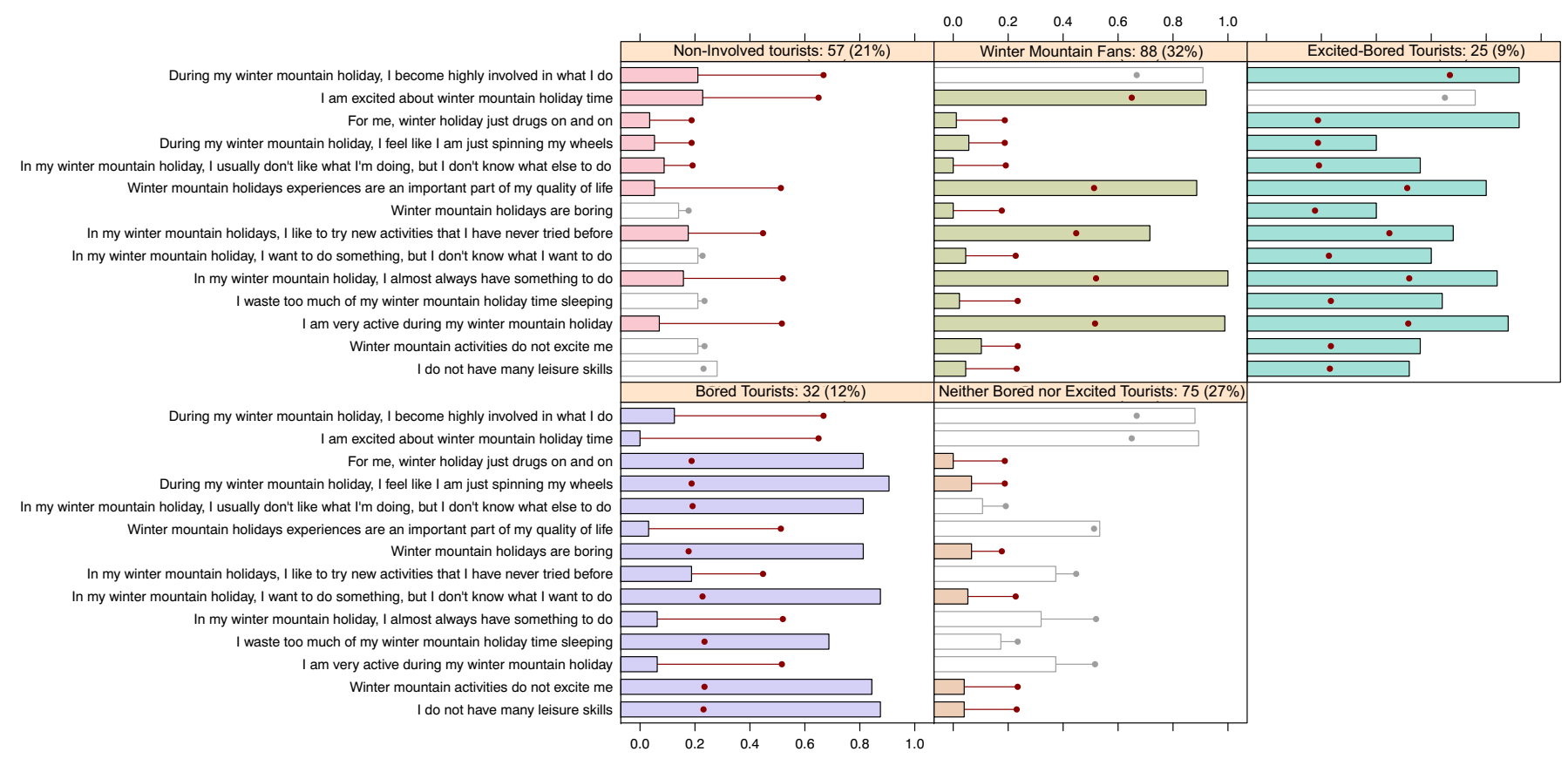

Fig. 2. Segment profile plot. Rates of the 14 items of the binarized LBS scale in the five segments. 


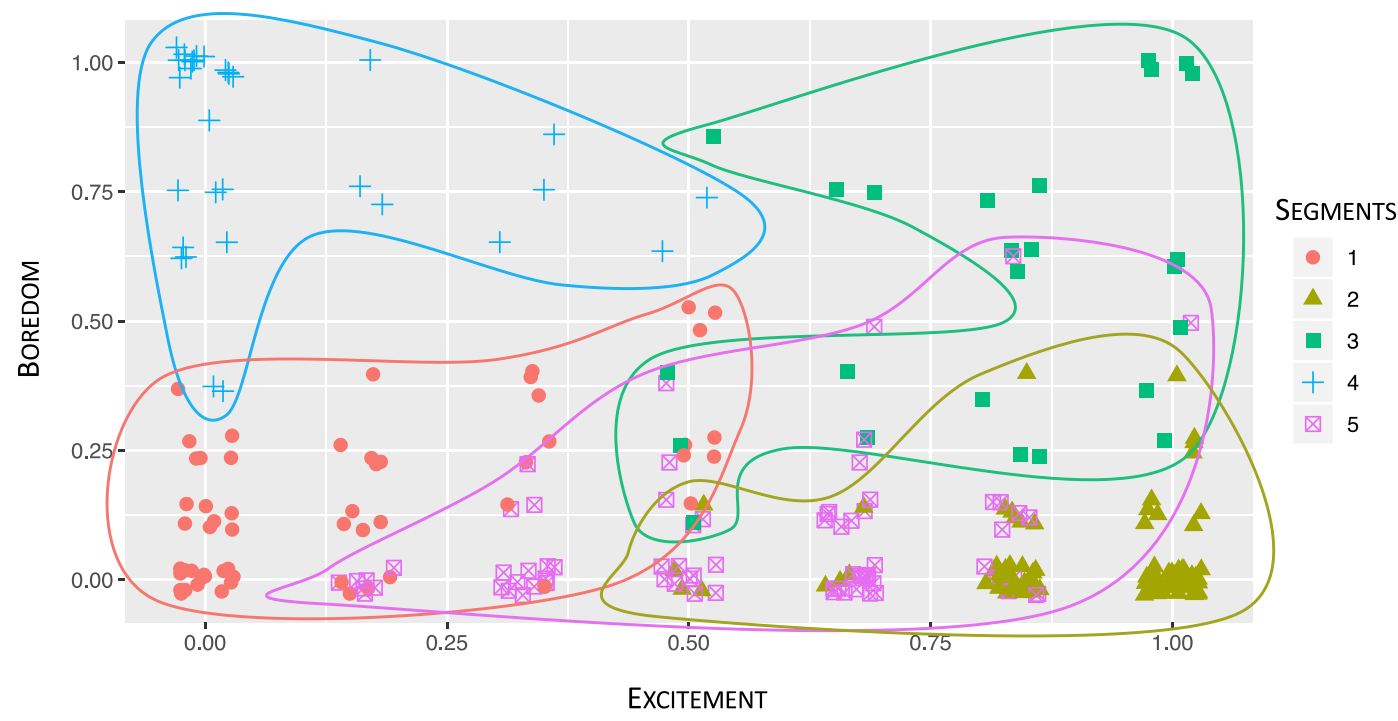

Fig. 3. Boredom and excitement across segments.

likely that winter tourists choose this city more for "logistics" reasons than for leisure. Indeed, if in a group of tourists there are non-skiers, Aosta can be a good compromise for all, but given the quiet life of the city, boredom is somehow the price to pay for being there. In the other locations, boredom is experienced more frequently in two situations: in very small locations (Torgnon), and where there are almost no alternative attractions beyond skiing (Cervinia, Gressoney and Pila).

The LBS was also integrated with two single indicators of boredom: the frequency of experiencing boredom during the winter holiday and its depth (Oppenheim, 1984), both measured on a 5-point scale. Results show that boredom is in fact more concentrated in two types of locations: the chief town Aosta and other minor, very small locations (for further details, see Table A1 in Appendix A). The boredom experience appears to be a light form of boredom, as shown by the very high percentages of "not bored/a little bored" and the corresponding low percentages of "quite/very bored".

The profile of the two segments who experience boredom can be further enriched with some traits and insights that may offer a deeper understanding. These segments have an interesting characteristic for our research: their profile is the one that shows almost the only significant differences compared to the sample averages for some traits. Focusing on these characterizing traits, we can further enrich their portrait:

- a higher percentage of Bored tourists are women (90.6\% vs an average of $57.4 \%$ ); the Excited-Bored segment presents a reverse situation where males are $68.0 \%$ vs an average of $42.2 \%$;

- Bored tourists are typically mothers (68.8\%), who are spending holiday with their family (75\%);

- Bored tourists are mostly families, while the Excited-Bored segment presents a higher percentage of friends (24\%);

- the size of the family of the Bored tourists and of the group of friends of the Excited-Bored tourists are quite high compared to other segments: groups of five people or more are a significantly higher percentage of the segments (28\% in both S3 and S4);

- the decision on the specific holiday has more often been a family decision for all the segments (average of $46.9 \%$ ), but in the case of Bored tourists the husband acts more often as an independent decision maker (28.1\%), and also the children exert a higher influence compared to other segments (3.1\%);

- tourist satisfaction for their holiday is quite high overall (85.1\%), with the only exception for Excited-Bored tourists, who show a lower degree of satisfaction and a significantly higher level of unsatisfaction/neutral attitude;

- correspondingly, the percentage of detractors in the Net Promoter Score is significantly higher in the segment of Bored tourists, while the percentage of promoters is the lowest. The behaviour of these tourists regarding the propensity to recommend is exactly the opposite of that of the Fans, which includes the most enthusiastic tourists;

Table 2

7-point LBS and binarized LBS segmentation (percentages are referred to the segment total).

\begin{tabular}{|c|c|c|c|c|c|c|}
\hline \multirow[t]{2}{*}{ Sum of LBS items (1-7) } & & \multicolumn{5}{|l|}{ Segments } \\
\hline & & $\mathrm{S} 1$ & $\mathrm{~S} 2$ & S3 & S4 & S5 \\
\hline \multirow{2}{*}{ All Items } & Highest $25 \%$ & $13(22.8 \%)$ & $10(11.4 \%)$ & $21(84.0 \%)$ & $26(81 . \%)$ & $11(14.7 \%)$ \\
\hline & Lowest $25 \%$ & $26(45.6 \%)$ & $17(19.3 \%)$ & $1(4.0 \%)$ & $0(0 \%)$ & $29(38.7 \%)$ \\
\hline \multirow{2}{*}{ Average of the 6 items related to excitement/max (42) } & Highest 25\% & 0.60 & 0.84 & 0.81 & 0.42 & 0.76 \\
\hline & Lowest $25 \%$ & 0.44 & 0.74 & 0.62 & - & 0.63 \\
\hline \multirow{2}{*}{ Average of the 8 items related to boredom/max (56) } & Highest 25\% & 0.59 & 0.45 & 0.67 & 0.76 & 0.52 \\
\hline & Lowest $25 \%$ & 0.35 & 0.20 & 0.30 & - & 0.25 \\
\hline
\end{tabular}


- the weather at the time of answering the questionnaire was worse for the Bored compared to the Excited-Bored tourists: cloudy ( $40.6 \%$ vs $24 \%$ ), with snow ( $28.1 \%$ vs $16 \%$ ), and only in few cases sunny ( $28 \%$ vs $40 \%$ ).

Tourists' values and motivations

As previously discussed, we are interested in investigating the predominance of specific values or motivations in the bored tourists' segments. The distribution of tourists' values (LOV scale), however, does not show any significant differences between the segments, despite the severe binarization of the LOV scale. Hence, values do not offer useful insights on the reasons why Bored tourists perceive more boredom during their holiday. We can only notice that they show above average ratings for the items related to security, self-respect, warm relationships and sense of accomplishment, which may be related to the larger presence of mothers with children in the two segments who experience boredom. This result is coherent with the idea that the same value can generate situationally different behaviors (Gnoth, 1997), and suggests that the LOV scale does not describe the complexity of the phenomenon under study.

A fairly similar situation results from the distribution of the ratings of the motivations proposed by Fodness (1994): there are very few differences between the five segments, and they are all related to the Bored tourists, who rate much lower than the average many motivations included in the knowledge function and in the utilitarian function. The items which show a statistically lower rating for the segment of Bored tourists compared to the average are for example: "It is important for me to experience different cultures and different ways of life", "I like to see how other people live", "I like to visit foreign cultures", "I want to see things while on vacation that I don't normally see", "I just like to travel, to go somewhere and to do something". All these items are clustered at the positive pole and are related to very active vacation themes, such as the desire to experience new cultures and the local life, to see how other people live, and to see new things. In summary, while most vacationers of winter mountain destinations interpret their holiday as an opportunity to learn and broaden their horizons also from a hedonic perspective, Bored tourists are less motivated by this need, which would require an attitude of openness to local culture and stimuli. This is why they are more prone to boredom.

The different motivations of the two segments of tourists who perceive boredom may stimulate some thoughts on the activities they would be more or less prone to practice. A stereotype could be that Bored tourists do nothing and, on the opposite, the Fans do everything. However, as anticipated, people who are used to having a structured everyday life may fear boredom even before perceiving it and, hence, engage in many activities.

\section{Activities across tourist segments}

Respondents were asked to indicate how much time they dedicate to specific activities using a 5-point scale ranging from never (1) to very much (5) (Derek et al., 2019). The list of activities was developed integrating Mauri (2019) with Moscardo et al. (1996) and Derek et al. (2019), choosing the activities adapted to winter mountain contexts. Table 3 shows the results for the total sample and for the five segments.

Statistics in Table 3 can be read (especially concerning S3 and S4) both vertically to analyse the time allocated to the different activities, and horizontally to compare segment means.

Reading Table 3 vertically, the most striking evidence is that the typical day of the winter mountain tourists is full of many sorts of activities; of these, the activity that takes almost half of the time on average is going to a restaurant and tasting local food. If on the one side the typical activities practiced in winter mountain destinations are downhill, cross-country skiing and snowmobiling (Heberlein et al., 2002), on the other side even passionate skiers (the Fans) dedicate a significant amount of time to food and beverage. Moreover, tourists who declare spending at least $50 \%$ of their time skiing ( $44 \%$ of the total sample, average time dedicated to skiing 4.01) spend almost all the other part of the day in activities related to local food and beverage (rated on average 2.86 , at the same level as the total sample).

Table 3

Activities practiced by winter mountain tourists across segments, in decreasing order of the total mean.

\begin{tabular}{|c|c|c|c|c|c|c|}
\hline Activities & Total sample & $\mathrm{S} 1$ & $\mathrm{~S} 2$ & S3 & S4 & S5 \\
\hline Restaurants, traditional food & 2.86 & $2.60^{\mathrm{a}}$ & 2.94 & 3.08 & 2.44 & 3.05 \\
\hline Alpine and cross-country ski & 2.59 & $1.98^{\mathrm{a}}$ & $3.47^{\mathrm{a}}$ & 2.96 & $1.53^{\mathrm{a}}$ & 2.36 \\
\hline Accompany husband/wife/children & 2.51 & 2.81 & $2.18^{\mathrm{a}}$ & 2.60 & $3.72^{\mathrm{a}}$ & $2.13^{\mathrm{a}}$ \\
\hline Sleep & 2.36 & 2.35 & $2.12^{\mathrm{a}}$ & 2.64 & 2.50 & 2.51 \\
\hline Wellness and relax & 2.32 & $1.98^{\mathrm{a}}$ & 2.14 & $3.00^{\mathrm{a}}$ & 2.50 & 2.48 \\
\hline Hikes in the snow & 2.27 & $2.02^{\mathrm{a}}$ & 2.48 & 2.60 & $1.75^{\mathrm{a}}$ & 2.32 \\
\hline Meet with friends & 2.18 & 2.00 & 2.27 & $3.28^{\mathrm{a}}$ & $1.47^{\mathrm{a}}$ & 2.15 \\
\hline Shopping & 2.13 & 2.00 & 1.97 & 2.48 & $2.50^{\mathrm{a}}$ & 2.15 \\
\hline Participate to local events & 2.05 & 1.86 & 2.03 & $2.92^{\mathrm{a}}$ & $1.69^{\mathrm{a}}$ & 2.09 \\
\hline Reading books & 2.01 & 2.00 & $1.77^{\mathrm{a}}$ & 2.16 & $2.72^{\mathrm{a}}$ & 1.95 \\
\hline Monuments and museums & 1.77 & $1.70^{\mathrm{a}}$ & 1.66 & $2.24^{\mathrm{a}}$ & 1.69 & 1.84 \\
\hline Nightlife, Saint-Vincent Casino & 1.49 & 1.30 & 1.47 & $2.04^{\mathrm{a}}$ & $1.25^{\mathrm{a}}$ & 1.59 \\
\hline
\end{tabular}

Note: $1=$ never; $2=$ some time; $3=$ about half of the time; $4=$ much time; $5=$ very much time. Significance level (difference from the sample mean). a $<0.1$. 
Those who ski very few hours during the day (average time 1.53 for Bored tourists) still dedicate almost half of their time to restaurants and traditional foods (2.44 on average). Local food emerges as a key component of the cultural traits of a destination for all tourists (Stephan et al., 2008) because it creates opportunities to learn not only about the geography of the place, but also about its roots and culture (Richards, 2002).

Differently from the summer season, the short days and cold temperatures of the winter season create constraints on the practicing of outdoor activities, though the same factors allow for the time needed to experience the place in closer, private and more intimate dimensions, such as relaxing at a local spa and/or thermal bath.

Mountain places may host important monuments and museums, but these do not seem to appeal to winter mountain tourists, except for the small segment of the Excited-Bored. This is not to mean that winter mountain tourists are not fond of cultural attractions, but that they prefer to experience the cultural dimension of the place partaking in other activities, such as going to restaurants and tasting the local cuisine. Similar research done in the summertime would probably produce different results, more in favour of visiting monuments and museums. Finally, a winter mountain destination does not seem to be the ideal place for night life and gambling at the casino.

Reading Table 3 horizontally, there are some activities that show significant differences between the five segments and the sample average: Alpine and cross-country skiing is more heavily practiced by the Fans; Excited-Bored tourists experience all the attractions of the place, particularly those related to wellness and relaxation, monuments and museums, and local events. Bored tourists dedicate less time to skiing and meeting friends, and more time to accompanying relatives and reading. This is in line with their demographic profile: women and mothers who are on holiday with their family and have children. Moreover, $71.9 \%$ of them stay in Pila, which is a ski station with only hotels and almost no stores: after accompanying their children who ski, and after reading books, if they want to do something else, they have either to take the cableway or the car to reach Aosta. It is not surprising that they experience boredom!

Since the other activities are not second compared to the other segments, boredom does not translate into passive behaviour, nor into unimaginative relaxation (as was the case in Ryan \& Glendon, 1998). These results may confirm our previous observation that people used to having a structured everyday life may fear boredom even before perceiving it, and, hence, book their leisure time in order to engage in many activities (Bench \& Lench, 2019).

\section{Tourist expenses}

Tourist expenses have been measured per capita on a daily average basis for activities that imply an economic outlay, and have been calculated as total spending divided by duration of stay and number of persons in the total party (as in Model 3 presented by Kozak et al., 2008). From Table 4, the average total daily spending per capita is $87.13 €$, a value that is not statistically different between segments (excepts for the Fans) due to the very high standard deviation not only of the total expenses, but also of all the expenses related to the specific activities. Expenses for activities are thus similar between segments. The high standard deviations signal that winter mountain tourist behaviour is highly segmented in terms of expenditures for the various activities rather than in terms of practiced activities. The comparison of the coefficients of variation (CV) of the two measures - time dedicated to a specific activity and spending for the same activity - shows in fact that the coefficients of variation of the expenses is never less than 2.5 times that of the activities, and for wellness the ratio between the first and the second CV climbs to almost 9 times (Table 5).

The very high standard deviation of the expenses has induced us to investigate "outliers", that is, tourists with a very high spending averages per day. There are two single respondents overall who show a daily total spending $>1000 €$, both included in the Excited-Bored segment. Considering the variables that significantly affect unit daily spending (Aguiló et al., 2017; Kozak et al., 2008), we checked the length of stay and the number of components of the family/group of these two respondents: they spent only one night at the destination (Aosta and Courmayeur) sleeping in hotel, and they were on holiday in 2 and 3, respectively. Their very high spending for different activities, such as accommodation, restaurant, skiing and spa is a signal of their willingness to experience the most luxurious and exclusive attractions of the place. In addition, high spending for souvenirs can be interpreted as the wish to bring home an important piece of the place's identity to evoke memories and have a physical reminder of the experience (Kong \& Chang, 2016; Kotler et al., 2004).

The results related to tourism expenditures further confirm the previous conclusion that those tourists who experience relatively more boredom not only have a day full of many activities, but they spend at least the same money as other tourists, and sometimes even more.

Table 4

Tourist expenditures: daily average per persona

\begin{tabular}{|c|c|c|c|c|c|c|c|}
\hline & Accommodation & Restaurant & Ski & Wellness (Spa) & Monuments and museum & Shopping (souvenir) & Total \\
\hline Total sample & $24,06 €$ & $19,35 €$ & $19,12 €$ & $9,15 €$ & $2,6 €$ & $12,86 €$ & $87,13 €$ \\
\hline $\mathrm{S} 1$ & $21,69 €$ & $21,73 €$ & $27,28 €$ & $9,99 €$ & $2,25 €$ & $17,83 €$ & $100,78 €$ \\
\hline $\mathrm{S} 2$ & $21,76 €$ & $18,5 €$ & $16,73 €$ & $4,74 €^{\mathrm{a}}$ & $2,29 €$ & $7,69 €^{\mathrm{a}}$ & $71,71 €^{\mathrm{a}}$ \\
\hline S3 & $42,64 €$ & $18,14 €$ & $21,64 €$ & $31,73 €$ & $5,12 €$ & $32,59 €$ & $151,85 €$ \\
\hline S4 & $24,86 €$ & $17,3 €$ & $19,11 €$ & $6,17 €$ & $0,73 €^{\mathrm{a}}$ & $8,75 €$ & $76,92 €$ \\
\hline S5 & $22,01 €$ & $19,81 €$ & $14,87 €$ & $7,41 €$ & $3,2 €$ & $10,33 €$ & $77,63 €$ \\
\hline
\end{tabular}

Significance level (difference from the sample mean)

a $<0.1$ 
Table 5

Coefficients of variation of time and spending for specific activities (time is not available for accommodation).

\begin{tabular}{|c|c|c|c|c|c|c|c|c|c|c|}
\hline & \multicolumn{2}{|c|}{ Restaurant } & \multicolumn{2}{|l|}{ Ski } & \multicolumn{2}{|c|}{ Wellness (Spa) } & \multicolumn{2}{|c|}{$\begin{array}{l}\text { Monuments and } \\
\text { museums }\end{array}$} & \multicolumn{2}{|c|}{ Shopping (souvenir) } \\
\hline & Time & Spending & Time & Spending & Time & Spending & Time & Spending & Time & Spending \\
\hline Mean & 2.86 & $19.35 €$ & 2.59 & $19.12 €$ & 2.32 & $9.50 €$ & $1.77)$ & $2.60 €$ & 2.13 & $12.86 €$ \\
\hline Standard deviation & 1.14 & $19.76 €$ & 1.42 & $28.25 €$ & 1.10 & $38.77 €$ & 0.87 & $6.44 €$ & 1.00 & $38.96 €$ \\
\hline $\mathrm{CV}$ & 0.40 & 1.02 & 0.55 & 1,48 & 0.47 & 4.08 & 0.49 & 2.48 & 0.47 & 3.03 \\
\hline $\mathrm{CV}$ spending/CV time & 2.56 & & 2.69 & & 8.61 & & 5.04 & & 6.45 & \\
\hline
\end{tabular}

\section{Implications for management in winter mountain destinations}

The segmentation of a sample of winter mountain tourists on the basis of their LBS scores results in five segments, with two of them experiencing boredom during their holiday. They are the smallest segments: $12 \%$ are the Bored tourists, and $9 \%$ are the Excited-Bored tourists. Individuals of the second segment experience some boredom during their stay, but the feeling of boredom does not prevent them from engaging in the many activities that the place offers. Boredom is related neither to unimaginative relaxation nor to laziness, but rather to a sort of super-activism (especially for the Excited-Bored tourists).

The typical day for tourists, and even more so for the ones who experience boredom, is activity-filled, and going to restaurants and tasting local foods is one of the activities that occupies most time. Breakfast, lunch and dinner routines in the mountains are not the same as in normal life, and each moment is an occasion to live local culinary traditions at their fullest. Food \& beverage in winter mountain places emerges, therefore, as a key strategic "ingredient" of the place branding because it allows for understanding the local culture in a very simple, immediate and enjoyable way.

Food \& beverage is also the second greatest expense after accommodation, has the lowest standard deviation and the lowest coefficient of variation. Ski sports, the main attraction of a winter mountain destination, are a highly segmented activity, as shown by its high $\mathrm{CV}$ : there are many passionate skiers who spend a lot of time skiing, but there are also tourists who ski very little or do not ski at all.

This has significant implications for the stakeholders managing winter mountain destinations, particularly in relation to marketing and communications strategies. While skiing and snow sports in general may represent the main attractions for winter mountain destinations, the empirical research shows that snow tourism is a more articulated phenomenon in which many different activities are combined, even in a single day. In the single 1 night +1 day of their vacation, the two tourists with the highest spending experienced many activities at their highest luxury tier, a further confirmation that there is a lot more beyond mountain and snow.

All the stakeholders involved in promoting winter mountain destinations should be aware of the complexity of the place experience, and of the willingness of tourists to live it at its fullest potential. Mountains, snow, and snow sports, which are the classic themes of communication, could be complemented with local food, traditions and cuisine, which represent an accessible key to understand the culture of the place.

\section{Conclusions, limitations and avenues for future research}

The goal of this paper was to shed some light on the existence of tourists who experience boredom during their holiday. The empirical research conducted in a winter mountain region confirms the existence of two segments of tourists who experience boredom in their holiday, which together make $21 \%$ of the tourists. The perception of boredom does not exclude the feeling of excitement, neither the participation in the many activities that the place offers, an evidence that at first sight may appear contradictory. While boredom has been traditionally associated to monotonous and repetitive activities, and to a low environmental stimulation, the situation in a winter holiday setting appears more complex and articulated.

The main contributions of our research are related to three domains: theory, marketing and public policy. These contributions, together with avenues for future research, are summarized in Table 6.

From a theoretical perspective, the validation of the LBS scale in a tourism setting revealed a result different from what supposed by Iso-Ahola and Weissinger (1990), and very close to that obtained by Kara et al. (2014): the core of the scale is not one single factor (boredom), but rather two opposite, that we named "Boredom" and "Excitement". We did not discover them through factor analysis, but rather looking at how tourists have distributed their ratings to the items of the LBS scale. Cluster analysis revealed that $12 \%$ of the tourists of a winter mountain destination show a higher perception of boredom and a low perception of excitement, while $9 \%$ of tourists show a higher perception of boredom but, at the same time, they feel excitement.

The majority of bored tourists (S3 and S4) stay in hotels (59.6\%) either in Pila (45.6\%) or Aosta (22.8\%), the chief town of the region, or in very small villages. The choice of Aosta may be a compromise for a group in which there are some members who do not ski. This also holds true for Pila, the only ski station that can be reached directly from the city centre of Aosta in just a few minutes. Boredom is a sort of price to be paid in smaller locations, whose size forces them to offer a narrower portfolio of activities.

Bored tourists are second to none in participating in all the activities the place offers (especially Bored-Enthusiastic tourists); they have a super-organized day full of activities and spend relatively more time accompanying husband/wife/children, sleeping, shopping, and reading books.

Concerning limitations, this study is focused on Italian tourists. While Aosta Valley is an internationally renowned tourist resort, the goal of our research was to investigate the feeling of boredom and its relationship with tourist motivations to visit the 
Table 6

Main contributions and avenue for future research.

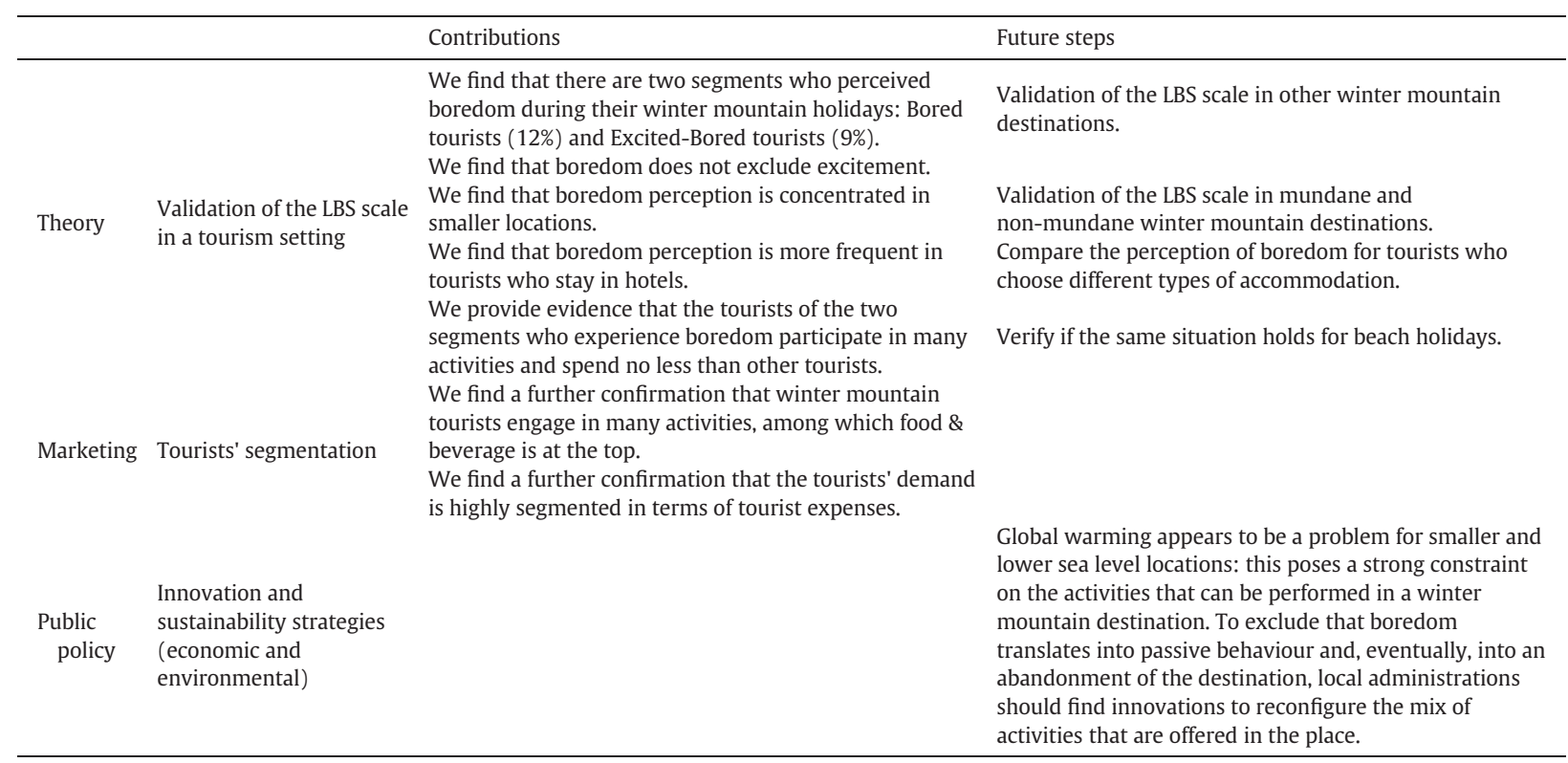

place, on the one side, and with tourists' activities and expenses, on the other. Given that motivations are strongly related to personal values, which may be country-specific, we decided to focus on Italians, who represent around 50\% of tourists in the winter season. Thus, a first possible extension of this research would be to study tourists from other countries, which in the case of the Aosta Valley are the UK, Sweden, Russia, and emerging nations, such as China and Brazil. Moreover, there is a recent evidence that tourists from different countries show different expenditure patterns (Aguiló et al., 2017).

A second avenue for future research could be to analyse different type of winter mountain destinations, such as mundane vs non-mundane, given that the perception of boredom appears more concentrated in smaller and/or more marginal locations; locations favoured by systematic abundance of "high quality" natural snow vs mountain destinations more penalized by global warming and, hence, less snow.

A third possible extension is to run the research in the summer season. Days in summer are longer, allowing for more time to dedicate to outdoor activities. The summer season attracts different types of tourists compared to those of the winter: the percentage of Italians increases from 50\% to almost 80\%, and closer countries, such as France, Switzerland and Germany, have a higher presence compared to that of the winter season.

On the same wave, the comparison between mountain destinations and sea destinations can reveal similarities and differences due to their diverse mix of activities, their different climate, and their different holiday routines.

From a marketing perspective, we find a further confirmation that winter mountain tourists engage in many activities, among which food \& beverage is at the top, and that the tourists' demand is highly segmented in terms of tourist expenses.

From a public policy perspective, our results can offer useful insights related to innovation and sustainability strategies. Global warming is a problem for smaller and lower sea level locations: this poses a strong constraint on the activities that can be performed in a winter mountain destination. To exclude that boredom translates into passive behaviour and, eventually, into an abandonment of the destination, local administrations should find innovations to reconfigure the mix of activities that are offered in the place.

COVID-19 has created a difficult time for the tourism industry. The 2019-2020 and also the 2020-2021 winter seasons imposed the closure of the ski stations. The future re-opening will be problematic due to many restrictions imposed by the pandemic. All the stakeholders involved in managing the destinations are at work to search for the most effective and efficient solutions to reshape experiences in all sectors, including accommodations, skiing, restaurants, spas and museums. Access to activities will be much more limited. Since tourists seem to like a day full of many activities, and even more so in the case of bored tourists, how will they cope with their boredom?

\section{Declaration of competing interest}

The authors declare that they have no known competing financial interests or personal relationships that could have appeared to influence the work reported in this paper.

\section{Acknowledgments}

The authors would like to express special thanks to Elena Irina Ungureanu, who hepled them to develop the survery. 


\section{Appendix A}

\section{Table A1}

Boredom frequency and depth in different locations.

\begin{tabular}{|c|c|c|c|c|c|c|c|c|}
\hline & Aosta & Cervinia & $\begin{array}{l}\text { Cogne } \\
\text { Valtournenche }\end{array}$ & Courmayeur & Gressoney & Pila & Torgnon & Other \\
\hline $\begin{array}{l}\text { "How often do you feel bored during your winter mountain holidays?" } \\
\text { never/sometimes }\end{array}$ & 0.51 & 0.53 & 0.83 & 0.64 & 0.25 & 0.56 & 0.50 & 0.64 \\
\hline often/very often & 0.49 & 0.47 & 0.17 & 0.36 & 0.75 & 0.44 & 0.50 & 0.36 \\
\hline $\begin{array}{l}\text { "How deeply do you feel bored during your winter mountain holidays?" } \\
\text { not/a little bored }\end{array}$ & 0.89 & 0.97 & 0.83 & 1.00 & 1.00 & 0.81 & 1.00 & 0.92 \\
\hline quite/very bored & 0.11 & 0.03 & 0.17 & 0.00 & 0.00 & 0.19 & 0.00 & 0.02 \\
\hline
\end{tabular}

\section{References}

Aguiló, E., Rosselló, J., \& Vila, M. (2017). Length of stay and daily tourist expenditure: A joint analysis. Tourism Management Perspectives, $21,10-17$.

Baloglu, S., \& Uysal, M. (1996). Market segments of push and pull motivations: A canonical correlation approach. International Journal of Contemporary Hospitality Management, 8(3), 32-38.

Barnett, L. A. (2005). Measuring the ABCs of leisure experience: Awareness, boredom, challenge, distress. Leisure Sciences, 27(2), 131-155.

Barnett, L. A., \& Klitzing, S. W. (2016). Boredom in free time: Relationships with personality, affect, and motivation for different gender, racial and ethnic student groups. Leisure Sciences, 28(3), 233-244.

Bench, S. W., \& Lench, H. C. (2019). Boredom as a seeking state: Boredom prompts the pursuit of novel (even negative) experiences. Emotion, $19(2), 242-254$.

Carr, N. (2002). The tourism-leisure behavioural continuum. Annals of Tourism Research, 29(4), 972-986.

Choong-Ki, L., Var, T., \& Blaine, T. W. (1996). Determinants of inbound tourist expenditures. Annals of Tourism Research, $23(3), 527-542$.

Crompton, J. L. (1979). Motivations for pleasure vacation. Annals of Tourism Research, 6(4), 408-424.

Dann, G. M. S. (1977). Anomie, ego-enhancement, and tourism. Annals of Tourism Research, 4(4), 184-194.

Dann, G. M. S. (1981). Tourism motivation: An appraisal. Annals of Tourism Research, 2(8), 187-219.

Davies, B., \& Mangan, J. (1992). Family expenditure on hotels and holidays. Annals of Tourism Research, 19(4), 691-699.

Decrop, A., \& Snelders, D. (2004). Planning the summer vacation: An adaptable process. Annals of Tourism Research, 31(4), 1008-1030.

Derek, M., Wozniak, E., \& Kulczyk, S. (2019). Clustering nature-based tourists by activity. Social, economic and spatial dimensions. Tourism Management, 75, 509-521.

Dolnicar, S., Crouch, G. I., Devinney, T., Huybers, T., Louviere, J. J., \& Oppewal, H. (2008). Tourism and discretionary income allocation. Heterogeneity among households. Tourism Management, 29(1), 44-52.

Dolnicar, S., \& Grün, B. (2007). Cross-cultural differences in survey response patterns. International Marketing Review, 24(2), 127-143.

Dolnicar, S., \& Grün, B. (2008). Challenging “factor-cluster segmentation”. Journal of Travel Research, 47, 63-71.

Dolnicar, S., \& Grün, B. (2013). "Translating” between survey answer formats. Journal of Business Research, 66(1), $1298-1306$.

Dolnicar, S., Grün, B., \& Leisch F. (2018). Market segmentation analysis. Understanding it, doing it, making it useful. Springer Nature.

Farmer, R., \& Sundberg, N. D. (1986). Boredom proneness: The development and correlates of a new scale. Journal of Personality Assessment, $50(1), 4-17$.

Fiske, D.W., \& Maddi, S.R. (2012). Functions of varied experience. Whitefish: Literary Licensing, LLC.

Fodness, D. (1994). Measuring tourist motivation. Annals of Tourism Research, 21(3), 555-581.

Fredman, P. (2008). Determinants of visitor expenditures in mountain tourism. Tourism Economics, 14(2), $297-311$.

Frochot, I., Elliot, S., \& Kreziak, D. (2017). Digging deep into the experience - Flow and immersion patterns in a mountain holiday. International Journal of Culture, Tourism and Hospitality research, 11(1), 81-91.

Gnoth, J. (1997). Tourism motivation and expectation formation. Annals of Tourism Research, 24(2), 283-304.

Haller, M., Hadler, M., \& Kaup, G. (2013). Leisure time in modern societies: A new source of boredom and stress? Social Indicators Research, 111(2), 403-434.

Heberlein, T. A., Fredman, P., \& Vuorio, T. (2002). Current tourism patterns in the Swedish mountain region. Mountain Research and Development, 22(2), 142-149.

Hill, A. B., \& Perkins, R. E. (1985). Towards a model of boredom. British Journal of Psychology, 76(2), 235-240.

Iso-Ahola, S. E., \& Weissinger, E. (1987). Leisure and boredom. Journal of Social and Clinical Psychology, 5(3), 356-364.

Iso-Ahola, S. E., \& Weissinger, E. (1990). Perceptions of boredom in leisure: Conceptualization, reliability and validity of the leisure boredom scale. Journal of Leisure Research, 22(1), 1-17.

Kahle, L. R., Beatty, S. E., \& Homer, P. (1986). Alternative measurement approaches to consumer values: The list of values (LOV) and values and life style (VALS). Journal of Consumer Research, 13(3), 405-409.

Kara, F. M., Gurbuz, B., \& Oncu, E. (2014). Leisure boredom scale: The factor structure and the demographic differences. Turkish Journal of Sport and Exercise, 16(2), $28-35$.

Kim, J. H., Ritchie, J. R. B., \& McCormick, B. (2012). Development of a scale to measure memorable tourism experiences. Journal of Travel Research, 51(1), 12-25.

Kong, W. H., \& Chang, T. -Z. (2016). Souvenir shopping, tourist motivation, and travel experience. Journal of Quality Assurance in Hospitality E Tourism, 17 (2), $163-177$.

Kotler, P., Nebenzahl, I. D., Lebedenko, V., Rainisto, S., Gertner, D., Clifton, R., ... Aaker, D. (2004). Where is place branding heading? Place Branding, 1(1), 12-35.

Kozak, M., Gokovali, U., \& Bahar, O. (2008). Estimating the determinants of tourist spending: A comparison of four models. Tourism Analysis, $13,143-155$.

Lee, T. -H., \& Crompton, J. (1992). Measuring novelty seeking in tourism. Annals of Tourism Research, 19(4), $732-751$.

Lehto, X. Y., Choi, S., Lin, Y. C., \& MacDermid, S. M. (2009). Vacation and family functioning. Annals of Tourism Research, 36(3), 459-479.

Lengieza, M. L., Hunt, C. A., \& Swim, J. K. (2019). Measuring eudaimonic travel experiences. Annals of Tourism Research, 74(C, $195-197$.

Li, M., \& Cai, L. A. (2012). The effects of personal values on travel motivation and behavioral intention. Journal of Travel Research, $51(4), 473-487$.

Liu, M., \& Wronski, L. (2018). Examining completion rates in web surveys via over 25,000 real-world surveys. Social Science Computer Review, 36(1), 116-124.

Madrigal, R., \& Kahle, L. R. (1994). Predicting vacation activity preferences on the basis of value-system segmentation. Journal of Travel Research, 32(3), 22-28.

Mannell, R. C., \& Iso-Ahola, S. E. (1987). Psychological nature of leisure and tourism experience. Annals of Tourism Research, 14(3), 314-331.

Mauri, C. (2019). Beyond mountain and snow. Holiday experiences in winter mountain destinations, in Foroudi, P., Mauri, C., Dennis, C., \& Melewar, T.C., Place Branding: Connecting Tourist Experiences to Places. Abingdon: Routledge.

Mauri, C., \& Turci, L. (2018). From ski to snow: Rethinking package holidays in a winter mountain destination. Worldwide Hospitality and Tourism Themes, 10(2), 201-210.

Mikulas, W. L., \& Vodanovich, S. J. (1993). The essence of boredom. The Psychological Record, 43(1), 3-12.

Miller, J. A., Caldwell, L. L., Weibright, E. H., Smith, E. A., Vergnani, T., \& Wegner, L. (2014). Was Bob Seger right? Relation between boredom in leisure and [risky] sex. Leisure Sciences, 36(1), 52-67.

Morgan, M., Lugosi, P., \& Ritchie, J. R. B. (2010). The tourism and leisure experience: Consumer and managerial perspectives. Bristol: Channel View Publications.

Moscardo, G., Morrison, A. M., Pearce, P. L., Lang, C. -T., \& O’Leary, J. T. (1996). Understanding vacation destination choice through travel motivation and activities. Journal of Vacation Marketing, 2(2), 109-122.

Nepal, S. K., \& Chipeniuk, R. (2005). Mountain tourism: Toward a conceptual framework. Tourism Geographies, 7(3), $313-333$. 
O'hanlon, J. F. (1981). Boredom: Practical consequences and a theory. Acta Psychologica, 49(1), 53-82.

Oppenheim, J.S. (1984). Perceived social competence, boredom, and the capacity for self-entertainment (Doctoral dissertation, University of Maryland).

Park, S., Woo, M., \& Nicolau, J. L. (2020). Determinant factors of tourist expenses. Journal of Travel Research, 59(2), 267-280.

Pearce, D. G. (1988). Tourist time-budgets. Annals of Tourism Research, 1(15), 106-121.

Pearce, P. L., \& Caltabiano, M. L. (1983). Inferring travel motivation from travelers' experiences. Journal of Travel Research, 12(2), 16-20.

Pechlaner, H., \& Smeral, E. (2014). Tourism and leisure. Wiesbaden: Springer Gabler.

Phillips, A. (1993). On kissing, tickling, and being bored: Psychoanalytic essays on the unexamined life. Cambridge: MA: Harvard University Press.

Ragheb, M. G., \& Merydith, S. P. (2001). Development and validation of a unidimensional scale measuring free time boredom. Leisure Studies, 20 (1), 41-59.

Richards, G. (2002). Gastronomy as a tourist product: The perspective of gastronomy studies. In A. M. Hjalager, HM, \& G. Richards (Eds.), Tourism and gastronomy. London: Routledge.

Rokeach, M. (1973). The nature of human value. New York: Free Press.

Rosselló-Nadal, J., \& He, J. (2020). Tourist arrivals versus tourist expenditures in modelling tourism demand. Tourism Economics, 26(8), 1311-1326.

Ryan, C., \& Glendon, I. (1998). Application of leisure motivation scale to tourism. Annals of Tourism Research, 25(1), 169-184.

Sainaghi, R. (2012). Tourist expenditures: The state of the art. Anatolia: An International Journal of Tourism E' Hospitality Research, 2(23), 217-233.

Shaw, S. M., Kleiber, D. A., \& Caldwell, L. L. (1995). Leisure and identity formation in male and female adolescents: A preliminary examination. Journal of Leisure Research, 27(3), 245-263.

Silva, C., Kastenholz, E., \& Abrantes, J. L. (2013). Place-attachment, destination image and impacts of tourism in mountain destinations. Anatolia, 24(1), 17-29.

Smith, S. L., \& Godbey, G. C. (1991). Leisure, recreation and tourism. Annals of Tourism Research, 18(1), 85-100.

Stephan, L., Smith, J., \& Xiao, H. (2008). Culinary tourism supply chains: A preliminary examination. Journal of Travel Research, 46(3), 289-299.

Stone, M. J. (2016). Deciding not to choose: Delegation to social surrogates in tourism decisions. Tourism Management, 57, 168-179.

Thornton, P. R., Shaw, G., \& Williams, A. M. (1997). Tourist group holiday decision-making and behaviour: The influence of children. Tourism Management, 18(5), 287-297.

Vodanovich, S. J. (2003). Psychometric measures of boredom: A review of the literature. The Journal of Psychology, 137(6), 569-595.

Wang, W. C., Wu, C. C., Wu, C. Y., \& Huan, T. C. (2012). Exploring the relationships between free-time management and boredom in leisure. Psychological Report, 110(2), 416-526.

Watkins, L., \& Gnoth, J. (2005). Methodological issues in using Kahle’s list of values scale for Japanese tourism behaviour. Journal of Vacation Marketing, 11(3), $225-233$.

Chiara Mauri works on marketing and retailing, and in particular on brand management, place branding, category management, and loyalty management. Consuelo R. Nava works on Bayesian econometrics, time series econometrics and applied statistics. 